\title{
Fechamento de diastema interincisal superior associado a dente supranumerário com intervenção ortodôntica: relato de caso clínico
}

\author{
Closure of superior intercernal diastema associated to supranumerary tooth with orthodontic intervention:
} clinical case

Cierre de diastema interincisal superior asociado a diente supernumerario con intervención ortodóntica: reporte de caso

\author{
Isabela Joane Prado SILVA ${ }^{1}$ \\ Anne Karoline Carvalho MAGALHÃES ${ }^{2}$ \\ Grace Kelly Martins CARNEIRO ${ }^{3}$ \\ Carla Oliveira FAVRETTO ${ }^{4}$
}

\begin{abstract}
${ }^{1}$ Graduanda da faculdade de Odontologia de Mineiros, FAMP - Faculdade Morgana Potrich, 75830-000 Mineiros-GO, Brasil ${ }^{2}$ Graduanda da faculdade de Odontologia de Mineiros, FAMP - Faculdade Morgana Potrich, 75830-000 Mineiros-GO, Brasil

${ }^{3}$ Mestre em Ortodontia pela São Leopoldo Mandic Campinas-SP, Professora de Ortodontia, FAMP-Faculdade Morgana Potrich, 75830-000 Mineiros-GO, Brasil ${ }^{4}$ Doutora em Ciência Odontológica, Aréa de Saúde Bucal da Criança, Faculdade de Odontologia de Araçatuba-SP (UNESP), Professora de Odontopediatria, FAMP-Faculdade Morgana Potrich, 75830-000 Mineiros-GO, Brasil
\end{abstract}

\begin{abstract}
Resumo
A abordagem correta e precoce de paciente infantil frente a alteração de desenvolvimento como a presença de dentes supranumerários modificando a oclusão normal tem apresentado resultados satisfatórios e importantes para manter a função e estética da cavidade bucal. O objetivo deste trabalho é apresentar um caso clínico com tratamento multidisciplinar envolvendo dente supranumerário e diastema interincisal em paciente infantil. Paciente com 7 anos de idade, gênero masculino, compareceu a clínica de Odontopediatria da Faculdade Morgana Potrich, com a queixa de um dente da frente torto. $\mathrm{O}$ exame clínico e radiográfico revelou a presença de um mesiodens causando um diastema na região anterior da maxila, com evidentes transtornos estéticos. O plano de tratamento estabelecido foi a remoção cirúrgica do dente supranumerário e tratamento ortodôntico para fechamento do diastema, possibilitando um resultado funcional e estético satisfatório, melhorando a qualidade de vida deste paciente. Dessa forma, o tratamento em paciente com pouca idade propiciou uma intervenção simples e com boa resolubilidade, devolvendo sua autoestima e bem-estar no seu convívio social.
\end{abstract}

Descritores: Dente Supranumerário; Diastema; Ortodontia; Criança.

\section{Abstract}

The correct and early approach on children patient in relation to developmental alteration as the presence of supernumerary teeth modifying normal occlusion has presented satisfactory and important results to maintain the function and aesthetics of the oral cavity. The objective of this work is to present a clinical case with multidisciplinary treatment involving supernumerary tooth and interincisal diastema in a child patient. A 7-year-old male patient attended the pediatric dentistry clinic at Morgana Potrich College, complaining of a crooked front tooth. The clinical and radiographic examination revealed the presence of a mesiodens causing a diastema in the anterior region of the maxilla, causing evident aesthetic disorders. The treatment plan established was the surgical removal of the supernumerary tooth and orthodontic treatment for closure of the diastema, allowing a satisfactory functional and aesthetic result, improving the quality of life of this patient. Thus, the treatment in a patient at young age provided a simple and good solvability intervention, giving back his self-esteem and well-being in his social life.

Descriptors: Tooth, Supernumerary; Diastema; Orthodontics; Child.

\section{Resumen}

El abordaje correcto y temprano del paciente infantil frente a las alteraciones de desarrollo como la presencia de dientes supernumerarios que modifican la oclusión normal ha presentado resultados satisfactorios e importantes para mantener la función y estética de la cavidad oral. El objetivo de este trabajo es presentar un caso clínico con tratamiento multidisciplinar que involucra un diente supernumerario y diastema interincisal en un paciente infantil. Paciente con 7 años de edad, género masculino, compareció a la clínica de odontopediatría de la facultad Morgana Potrich, con queja de un diente al frente del otro. Al examen clínico y radiográfico se reveló la presencia de un mesiodens causando diastema en la región anterior del maxilar, con evidentes trastornos estéticos. El plan de tratamiento establecido fue la remoción quirúrgica del diente supernumerario y tratamiento ortodontico para cierre del diastema, posibilitando un resultado funcional y estético satisfactorio, mejorando la calidad de vida de este paciente. De esta forma, el tratamiento en un paciente con poca edad propicio una intervención simple y con buena resolución, devolviendo su autoestima y bienestar en su convivencia social.

Descriptores: Diente Supernumerário; Diastema; Ortodoncia; Niño.

\section{INTRODUÇÃO}

$\mathrm{Na}$ Odontologia atual, os odontopediatras tem trabalhado muito a importância da saúde bucal, com acompanhamento desde a erupção dos primeiros dentes decíduo, a fim de oferecer prevenção como melhor forma de tratamento ao paciente. Esse acompanhamento acontece de forma complexa, pois tanto alterações fisiológicas quanto emocionais são acompanhadas pelo profissional, permitindo intervenções oportunas e muitas vezes precoces frente a diversas necessidades bucais, como nos casos com alterações de desenvolvimento. A presença de dentes supranumerários excede qualquer cuidado preventivo, necessitando de uma abordagem curativa oportuna frente cada caso.

Dentes supranumerários são aqueles que se desenvolvem além da série normal ${ }^{1,2}$, com maior incidência na maxila do que na mandíbula ${ }^{3}$. São chamados de mesiodens quando erupcionam entre os incisivos centrais superiores, geralmente invertidos na região palatina, ${ }^{4,5}$ seu tamanho e forma são variados, sendo a maioria sob forma rudimentares $\mathrm{e}$ menores que incisivos normais.

Sua etiologia ainda não está bem definida, mas acredita-se que esteja relacionada à hiperatividade da lâmina dentária, traumatismo ou mesmo desordens hereditárias ${ }^{6}$. A presença de dente supranumerário pode retardar ou impedir a erupção dos dentes permanentes sucessores, ocasionando nos dentes adjacentes desvios de erupção ou giroversões ${ }^{7}$, reabsorção radicular de dentes adjacentes ${ }^{8}$, formação 
de cistos com destruição óssea ${ }^{9}$, e apinhamentos, prejudicando tanto a estética, fonética ${ }^{8}$, como também o convívio social dos pacientes.

Dessa forma, a presença de mesiodens muitas vezes assintomática se torna perceptível frente a alterações do padrão normal de oclusão, causando alguns transtornos como os diastemas interincisais, que é definida como ausência de ponto de contato entre dentes consecutivos, podendo ser ou não fisiológica $^{10}$, A associação de ambas as alterações geralmente tem seu diagnóstico relacionado a pacientes jovens, em idade escolar, não sendo raro, principalmente nas últimas décadas, a busca por tratamento em virtude de episódios de bulling. Sendo de extrema importância identificar os motivos pelo qual a criança não quer comparecer mais a escola e procurar resolvê-lo com o tratamento adequado para que o mesmo não sofra por esta variação de normalidade. Gatto et al. ${ }^{11}$ cita que uma aparência dental desagradável pode estigmatizar uma pessoa e prejudicar a autoestima.

Assim, o objetivo desse trabalho é relatar através de um caso clínico a abordagem multidisciplinar envolvendo dente supranumerário e diastema interincisal em paciente infantil, ressaltando a importância do diagnóstico e intervenção clínica oportuna realizada em tempo adequado.

\section{CASO CLÍNICO}

Paciente I.H.A., de 7 anos e 8 meses de idade, procurou a clínica de Odontopediatria da Faculdade Morgana Potrich, Mineiros - GO, queixando-se de ter "um dente da frente torto". Após a anamnese, exame clínico extra e intra-oral e análise radiográfica, constatou-se a presença de um dente supranumerário rudimentar semi-incluso localizado na linha média da maxila (mesiodens), com evidentes transtornos estéticos (Figura 1), além de lesões cariosas nos dentes 55, 65, 74 e 84 .

A presença do supranumerário fez com que o dente 21 erupcionasse em posição ectópica, ocupando o lugar do dente 22, impedindo sua erupção. Devido a necessidade de um tratamento multidisciplinar, foi solicitada documentação ortodôntica. Mediante sua análise, diagnosticou-se que o paciente era portador de má-oclusão classe I, padrão de crescimento da face mesocefálico e perfil reto.

Na primeira fase do tratamento foi proposto a exodontia imediata do mesiodente, minimizando os problemas estéticos e para posteriormente permitir a recuperação do espaço através da movimentação ortodôntica. A cirurgia iniciou com a assepsia do campo operatório, anestesia infiltrativa do nervo alveolar superior anterior e bloqueio regional do nervo nasopalatino. Em seguida, realizou-se a sindesmotomia e a remoção do dente supranumerário (Figura 2). Após a remoção cirúrgica, foram aguardados aproximadamente 60 dias para uma cicatrização adequada e neoformação óssea da região.

Neste momento, a intervenção ortodôntica foi iniciada com a instalação do aparelho removível composto de acrílico em toda extensão do palato, adaptando um arco de Hawley para fixação do aparelho, evitando a vestibularização excessiva dos dentes, assim como grampos auxiliares de fixação e molas digitais duplas para mesialização dos dentes. Para as ativações removia o aparelho da boca do paciente e com uso do alicate 139 ativava a mola até obter uma pressão nos dentes quando instalado novamente na boca, ativando a cada 15 dias, com finalidade de fechar o espaço remanescente. Após três meses observou-se um fechamento satisfatório do diastema, prosseguindo com a ativação do aparelho até o fechamento total com 5 meses. Esse aparelho permanecerá em uso por mais 6 meses para garantir a estabilidade desse dente. A função e estética alcançada ao final desse período foram satisfatórias, no entanto o paciente ainda precisa de uma ortodontia corretiva para alinhamento de todos os dentes (Figura 3).
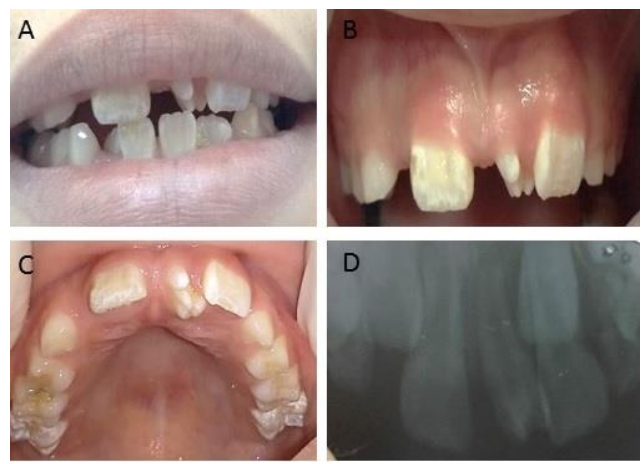

Figura 1: (A) Sorriso inicial. (B) Mesiodens vista frontal.(C) Mesiodens vista oclusal.(D) Exame radiográfico inicial.
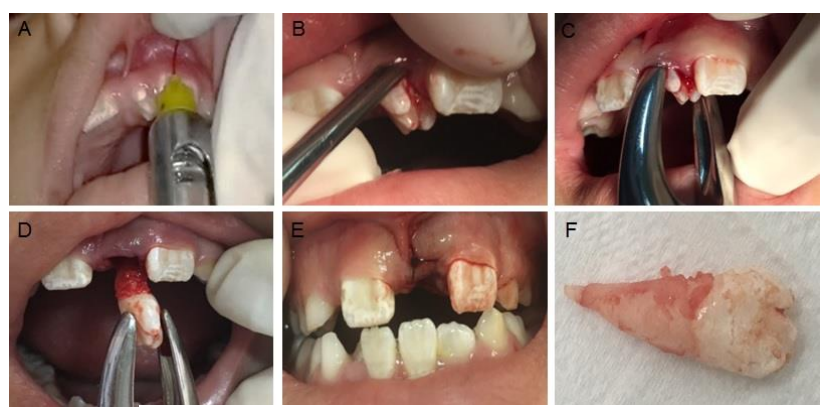

Figura 2: (A) Anestesia Infiltrativa. (B) Luxação. (C) Remoção com fórceps. (D) Dente supranumerário. (E) Sutura. (F) Mesiodens.
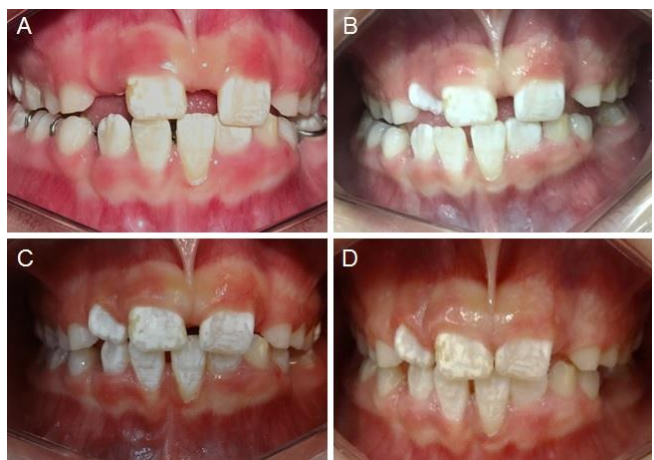

Figura 3: Ativações: (A) Após primeira ativação. (B) Após a terceira ativação. (C) Após a sexta ativação. (D) Caso final. 


\section{DISCUSSÃO}

A ação primária de acompanhamento do crescimento e desenvolvimento é essencial para a articulação de atividades de prevenção e intervenção ${ }^{12}$, fundamentando o papel do cirurgião dentista na supervisão da saúde bucal desde o nascimento do bebê. Sua importância está ancorada na prevenção, incorporando hábitos saudáveis de higienização e controle dietético prevenindo a instalação dos males bucais como também na busca pela detecção precoce, com o objetivo de possibilitar a cura em micro níveis, por meio da intervenção mínima, no tratamento de lesões irreversíveis ${ }^{13}$.

A presença de um dente supranumerário, semi incluso, localizado na linha média da maxila do paciente estabelece como principal queixa, o comprometimento estético. Campos et al. ${ }^{14}$ relatam que cerca de $90 \%$ dos dentes supranumerários situase na maxila, sendo o mesiodens representado em média por $80 \%$ dos $\operatorname{casos}^{15}$, a forma mais prevalente de dentes supranumerários na dentição permanente, não sendo uma condição rara, variando entre $0,09 \%$ e $2,05 \%$ em diferentes estudos ${ }^{16}$.

O diagnóstico foi estabelecido através do exame radiográfico, excluindo qualquer outra hipótese. A conduta terapêutica indicada foi a exodontia imediata, que justifica a remoção do mesiodens afim de prevenir a instalação de uma má oclusão. Vários autores idealizam a remoção cirúrgica $\operatorname{logo}$ após a realização do diagnóstico, visando à preservação da oclusão normal do paciente, bem como para precaver interferências de erupção e formação do dente adjunto ${ }^{5,17-19}$.

$\mathrm{Na}$ presença de diastemas, a remoção cirúrgica é ainda mais indicada, pois contribui para erupção espontânea e correta do sucessor permanente, evitando assim o deslocamento da linha mediana a fim de acautelar procedimentos cirúrgico/ortodôntico com elevado nível de complexidade $^{20,21}$. No entanto, no caso relatado já havia causado um comprometimento da oclusão com a transposição do dente 21 , além de um considerável diastema interincisal.

A busca pelo paciente ao tratamento foi de certa forma tardia, o que contribuiu para o sucesso cirúrgico devido ao comportamento físico e emocional satisfatório e a intervenção ortodôntica pelos dentes envolvidos como os adjacentes por possuírem estágios de formação radicular e erupção avançada.

A intervenção ortodôntica foi iniciada logo após o tempo necessário para o reparo pós-cirúrgico. O aparelho eleito foi um removível com molas, pelo fato de desejar-se um movimento de angulação dos incisivos para mesial. Quanto maior a amplitude do diastema, maior a alteração na angulação dentária gerada pelas molas digitais ${ }^{22}$. Contribuiu também para escolha desse aparelho o fato dos dentes envolvidos não apresentarem rizogênese completa, justificando a escolha das molas para possibilitar uma movimentação branda. Além disso, ao alcançar o resultado desejado, o aparelho removível deve permanecer como contenção até a irrupção completa dos incisivos laterais como foi feito no presente caso $^{17}$

A possibilidade do diagnóstico precoce nesses casos coincide com a época escolar das crianças, ou seja, quando a criança aumenta seu contato social, inserida em grupos de amigos e familiares, fato que vem sendo relacionado com episódios de bullying por diversos motivos. O comprometimento estético do paciente resulta em desajustes que irão influenciar todos os setores da vida do indivíduo inclusive estimular o bullying ${ }^{23}$. Por isso, frente à cooperação do paciente, o tratamento foi iniciado imediatamente.

CONCLUSÃO

O diagnóstico precoce do mesiodens é importante para evitar algumas complicações. Contudo, quando a identificação é feita após a instalação de problemas que alterem a oclusão normal do paciente, é imprescindível a determinação de um bom plano de tratamento. A presença de diastema associado ao supranumerário prevê um tratamento multidisciplinar, incluindo remoção cirúrgica cautelosa e tratamento ortodôntico seguro e eficaz. O sucesso no tratamento contribui para inserção do paciente no seu convívio social, dandolhe autoestima e qualidade de vida, evitando-se apelidos pejorativos e o bullying.

\section{REFERÊNCIAS}

1. Russell KA, Folwarczna MA. Mesiodens diagnosis and management of a common supernumerary tooth. J Can Dent Assoc. 2003;69(6):362-66.

2. Khandelwal V, Nayak AU, Naveen RB, Ninawe N, Nayak PA, Sai Prasad SV. Prevalence of mesiodens among six-to seventeen-year-old school going children of Indore. J Indian Soc Pedod Prev Dent. 2011;29(4):288-93.

3. Yusof WZ. Non-syndrome multiple supernumerary teeth:Literature review. J Can Dent Assoc. 1990;56(2):147-49.

4. Hong J, Lee DG, Park K. Retrospective analysis of the factors influencing mesiodentes eruption. Int J Paediatr Dent. 2009;19(5):343-48.

5. Webwe FN. Dientes supernumerarios. Dent Clin Noth Am. 1980;23:302-11.

6. Issao M, Kahtalian LY. Dentes supranumerários na região ântero-superior na dentição mista. Rev Fac. Odont S Paulo. 1968;6(2):137-50.

7. Assed A, Borsatto MC, Freitas AC. Anomalias dentárias. São Paulo: Artes Médicas; 2005.

8. Berthold TB, Benemann E. Anomalia do número de dentes: Anodontia e supranumerário. Rev 
Odonto Ciênc. 1996;11(22):101-9.

9. Cal Neto JOAP, Cunha DL. Diastemas Interincisais Superiores Associados a Dentes Supranumerários - Considerações Clínicas e Relato de um caso. J Bras Ortodon Ortop Facial. 2002;7(39):239-44.

10. Raveli DB, Chiavini PCR, Pinto AS, Sakima MT, Martins LP, Melo ACM. Diastema interincisal. Fatores etiológicos: relatos de casos clínicos. J Bras Ortodon Ortop Facial. 1998;3(18):36-42.

11. Gatto RCJ, Garbin AJI, Corrente JE, Garbin CAS. Nível da autoestima de adolescentes brasileiros vítimas de bullying e sua relação com a necessidade de tratamento ortodôntico. RGO Rev Gaúch Odontol. 2017;65(1):30-6

12. Corso ACT, Zeni LAZR, Heidrich EMC, Kleine L, Closs G, Botelho LJ et al. Crianças préescolares e o impacto da assistência pública sobre seu crescimento. Rev Ciências da Saúde. 1996;15:29-46.

13. Mickenautsch S. An introduction to minimum intervention dentistry. Singapore Dent J. 2005;27(1):1-6.

14.Campos LM, Silva SREP, Imparato JCP, Pinheiro SL. Dente supranumerário rudimentar: relato de caso. JBC: J Bras Clin Odontol Int. 2002;6(32):129-32.

15.Garcia Junior IR, Coradazzi LF, Hasse PN, Manfrin TM. Remoção cirúrgica de mesiodens para erupção tardia dos incisivos centrais superiores - relato de caso clínico. Rev Bras Cir Implantodont. 2000; 7(27):6-10.

16. Marchetti G, Oliveira RV. Mesiodens - dentes supranumerários: diagnóstico, causas e tratamento. Uningá Review. 2015;24(1):19-23.

17. Almeida RR, Isbralde CMB, Ramos AL, Terada HH, Ribeiro R, Carreiro LS. Supranumerários Implicações e procedimentos clínicos. Rev Dental Press Ortodon Ortop Fac. 1997;2(6):91-108.

18.Cachapuz PF, Siqueira FS, Prietsch JR. Tratamento ortodôntico interceptativo de maloclusão causada por mesiodente: relato de caso. Rev Fac Odontol Porto Alegre. 2002;43(1):18-22.

19.Mc Donald RE. Odontopediatria. 5.ed. Rio de Janeiro: Guanabara Koogan; 1991.

20.Solares R. The complications of late diagnosis of anterior supernumerary teeth: Case report. ASDC J Dent Child. 1990;57(3):209-11.

21.Freitas MR, Henriques JFC, Martins DR, Scavone Jr H. Dentes supranumerários. Relato de um caso acompanhado durante dez anos. Ortodontia. 1993;26(1):92-7.

22. Almeida RR, Garib DG, Almeida-Pedrin RR, Almeida MR, Pinzan A, Junqueira MHZ. Diastema interincisivos centrais superiores: quando e como intervir? R Dental Press Ortodon Ortop Facial. 2004;9(3):137-56.
23.Boffi JC, Franzin LCS. Bullying e a atuação da Odontologia. Uningá Review. 2017;29(2):38-41.

\section{CONFLITO DE INTERESSES}

Os autores declaram não haver conflitos de interesse.

\section{AUTOR PARA CORRESPONDENCIA}

\section{Carla Oliveira Favretto}

carlafavretto@fampfaculdade.com.br

Submetido em 13/12/2018

Aceito em 12/03/2019 